\title{
Preface
}

Eva Gutheil* and Jürgen Troe

\section{Congratulations to Henning Bockhorn}

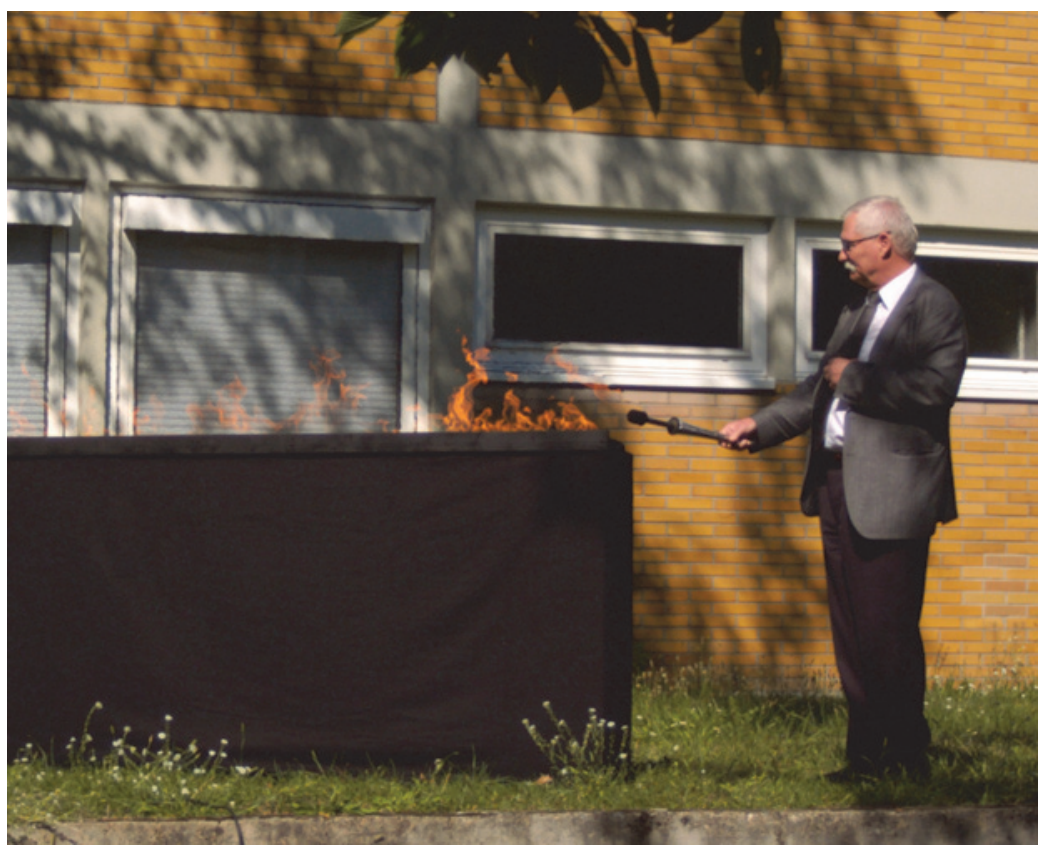

This special issue is dedicated to Henning Bockhorn on the occasion of his $70^{\text {th }}$ birthday which he celebrated on July 14, 2014. It honors his achievements in combustion and chemical engineering as well as his numerous activities in the communities of these fields. The issue, which might be entitled "Combustion", comprises three volumes with 26 articles submitted from renowned sci-

\footnotetext{
*Corresponding author: Eva Gutheil, Interdisciplinary Center for Scientific Computing, Heidelberg University, Heidelberg, Germany, e-mail: gutheil@iwr.uni-heidelberg.de Jürgen Troe: Max-Planck-Institute for Biophysical Chemistry, Göttingen, Germany
} 
entists from all over the world. The large number of contributions from Henning's colleagues and former students reflects both his outstanding reputation and the friendship that he has maintained with so many people over the last decades.

Henning received his $\mathrm{PhD}$ and Habilitation degrees in Chemical Engineering from the Technical University of Darmstadt, working with Professor Fritz Fetting. He spent some time with Ken Bray at Cambridge University in the UK, before he became professor at the Interdisciplinary Center for Scientific Computing at Heidelberg University. From here he moved to the University of Kaiserslautern and, finally, to the Technical University of TU Karlsruhe (now Karlsruhe Institute for Technology) where he became Professor for Chemical Engineering and, in 1998, also director of the Engler-BunteInstitute for Combustion Technology. He has written numerous brilliant original articles and reviews. Actually he is serving as the Chairman of the German Section of the Combustion Institute. Among his distinctions one may mention in particular the DECHEMA award for outstanding contributions to the field of modeling interactions between turbulence and chemical reactions in chemically reacting flows, and the Gerhard Damköhler Medal of the DECHEMA-GVC for outstanding scientific contributions to combustion science.

On October 24, 2014, Henning gave his farewell lecture at Karlsruhe with special emphasis on novel developments in the field of energy conversion. He also discussed the link between sound and smoke or, in other words, the relation between combustion and music which reflects Henning's personal interests. He arrived at challenging conclusions about wave theory, comparing sound from his trumpet and impressive combustion noise. This was certainly a most fascinating and enjoyable lecture for a large audience.

Henning has many hobbies which he always tried to combine with his activities in combustion. His motorcycle tour through North America on the occasion of the Seattle Combustion Symposium and his performance on French horn and trumpet at the occasion of his farewell lecture are legendary examples.

We know that Henning continues to be an active scientist: he goes to his office every day, just as he did when he was officially employed. He still spends more time with his research than with his wife, as he states with some regret. Currently, he is working on a new textbook on Technical Chemistry, for which we wish him all success. We hope that he can enjoy many more happy, healthy and active years, with his family and in our community. He promises that we will meet him at various conferences all over the world, this year and beyond. 
For me, Eva Gutheil, it was a pleasure to meet Henning in the beginning of the 80ies, just after finishing my Diploma in Mathematics and Computer Science. At that time he was courageous enough to let me pursue my PhD work in Chemical Engineering with him and Fritz Fetting, the latter being my official supervisor. Later, I followed Henning into his former position at the Interdisciplinary Center for Scientific Computing at Heidelberg University, where he had taken up the position of Jürgen Warnatz several years before.

For me, Jürgen Troe, it was a pleasure to have been formally something like "the boss" of Henning for a couple of years, when I served as the Chairman of the Board of Karlsruhe University, while at the same time I was a member of the German Section of the Combustion Institute under his Chairmanship.

We both were happy to act as Co-Guest Editors for the present issue of the Zeitschrift für Physikalische Chemie and we take the opportunity to thank all colleagues who contributed. This is our gift to an extraordinary scientist, teacher, colleague, and friend.

Eva Gutheil and Jürgen Troe, Heidelberg and Göttingen, February 2015 